\title{
Syphilis screening in the Blood Transfusion Service: a report of four years' experience with the Treponema pallidum haemagglutination assay and the subsequent development of a rapid "spin" method
}

\author{
A PUCKETT, G PRATT \\ From the Regional Blood Transfusion Centre, John Radcliffe Hospital, Headington, Oxford
}

SUMMARY A comparison of cardiolipin and a modified Treponema pallidum haemagglutination assay (TPHA) method over a four year period confirmed the superior sensitivity and specificity of TPHA. In 86495 new donor sera $19(0.02 \%)$ confirmed positive results were detected by TPHA, 10 of which did not react by the cardiolipin test. In 150789 antenatal samples 49 confirmed positive results were found by TPHA, 30 of which did not react by cardiolipin. No cardiolipin positive, TPHA negative samples were confirmed as positive by the absorbed fluorescence treponemal antibody test, and overall $78 \%$ of cardiolipin reactions gave false biological positive results. Cardiolipin tests were continued only because of their speed.

A further modification ("spin") of the TPHA has now been developed which is rapid, sensitive, and inexpensive, and in testing 21807 sera, gave results equivalent to those of the previous "settle" method. Serious consideration should be given to dispensing with cardiolipin tests.

Transfusion syphilis, although now rare, does still occur, ${ }^{12}$ and although routine screening of blood donors for syphilis has been called into question, ${ }^{3}$ it is still a legal requirement. Furthermore, there is an increasing tendency to use blood products which have been held at $22^{\circ} \mathrm{C}$, at which temperature Treponema pallidum can survive for longer periods than at the normal refrigeration temperature of $4^{\circ} \mathrm{C}$. There is thus a continuing need for an effective, practicable, and economical serological test.

The cardiolipin slide test for lipodial antibody has been relied on for many years, and in some centres has been adapted for use on automated blood grouping machines. In this centre the manual method has been preferred because of its greater sensitivity. Barbara et al tested 36500 donor sera and obtained nine confirmed positive results using the manual cardiolipin method, but only two with the automated method. In the same series he obtained 39 confirmed positive results using a modified Treponema pallidum haemagglutination assay (TPHA), indicating its increased sensitivity over cardiolipin tests. ${ }^{4}$

TPHA is widely used as a specific screen for syphilis but in its standard form is considerably more ex-

Accepted for publication 19 May 1987 pensive than cardiolipin. (TPHA is $28 \mathrm{p}$ per test, cardiolipin $0.53 \mathrm{p}$ per test. All prices quoted are exclusive of VAT and as of December 1986). To overcome this a miniaturisation of the Fujirebio TPHA was developed $^{5}$ using Terasaki rather than microtitre plates, which produced a considerable saving in reagents (1.24p per test). This technique takes two to three hours and was used routinely in this centre between 1982 and 1986 with a cardiolipin test (RPRBecton Dickinson). Sera showing a positive reaction in either test were referred to the Oxford Public Health Laboratory for confirmation with the absorbed fluorescence treponemal test (FTA-ABS). Table 1 shows the results from 86945 new donor sera, and table 2 those from 150789 antenatal sera.

Taken together, the results from these tables show that the modified TPHA was sensitive- 68 confirmed positive results compared with 28 detected by cardiolipin - and it was also more specific - $16 \%$ were false biological positive results compared with $78 \%$ of cardiolipin tests that were false biological positive results. (Most of the TPHA false positive results were detected at the beginning of the period when the cut off threshold was still being established. Now, only $4 \cdot 1 \%$ of our TPHA positive results are false biological positives). 
Table 1 Syphilis serology from 86945 new donor sera (Oxford RTC 1982-1986)

\begin{tabular}{llllrr}
\hline & Cardiolipin & TPHA & FTA & No(Total) \\
\hline False positive results & Positive & Positive & Negative & 0 & 2 \\
& Negative & Positive & Negative & 29 & 31 \\
& Positive & Negative & Negative & 29 & 9 \\
True positive results & Positive & Positive & Positive & 9 & 10 \\
& Negative & Positive & Positive & 10 & 0 \\
& Positive & Negative & Positive & 0 \\
\hline
\end{tabular}

Table 2 Syphilis serology from 150789 antenatal sera (Oxford RTC 1982-1986)

\begin{tabular}{|c|c|c|c|c|c|}
\hline & Cardiolipin & $T P H A$ & $F T A$ & No(T & \\
\hline False positive results & $\begin{array}{l}\text { Positive } \\
\text { Negative } \\
\text { Positive }\end{array}$ & $\begin{array}{l}\text { Positive } \\
\text { Positive } \\
\text { Negative }\end{array}$ & $\begin{array}{l}\text { Negative } \\
\text { Negative } \\
\text { Negative }\end{array}$ & $\left.\begin{array}{r}0 \\
11 \\
72\end{array}\right\}$ & 83 \\
\hline True positive results & $\begin{array}{l}\text { Positive } \\
\text { Negative } \\
\text { Positive }\end{array}$ & $\begin{array}{l}\text { Positive } \\
\text { Positive } \\
\text { Negative }\end{array}$ & $\begin{array}{l}\text { Positive } \\
\text { Positive } \\
\text { Positive }\end{array}$ & $\left.\begin{array}{r}19 \\
30 \\
0\end{array}\right\}$ & 49 \\
\hline
\end{tabular}

Table 3 Results of TPHA testing of syphilis serology (Panel 405 from the Division of Microbiological Reagents and Quality Control)

\begin{tabular}{lllc}
\hline Specimen & Expected results & "Spin" method & "Settle" method \\
\hline 1451 & Negative & Negative & Negative \\
1452 & Positive & $1 / 320$ & $1 / 512$ \\
1453 & Positive & $1 / 20$ & $1 / 32$ \\
1454 & Negative & Negative & Negative \\
\hline
\end{tabular}

These results cast doubt on the value of using cardiolipin as a routine screening test. Firstly, there were no confirmed positive results which reacted only by cardiolipin and so would have been missed by TPHA. Secondly, there were a large number of false positive results: $78 \%$ of all cardiolipin tests were not confirmed by FTA. The further investigation of these caused much unnecessary work, time, and cost to the centre, quite apart from trouble and anxiety to the donors and patients concerned-with no benefit to them. It has been suggested, however, that relying only on TPHA might lead to cases of early primary syphilis being missed. ${ }^{6}$ This view is not supported by Barbara et al, who tested 15 sera from patients with early primary syphilis by cardiolipin and modified TPHA. Thirteen sera reacted with cardiolipin; all 15 reacted with modified TPHA. ${ }^{7}$ Cardiolipin methods do have the advantage of being rapid, whereas TPHA tests take two to three hours. To overcome this the Oxford TPHA method was further modified ("spin") by centrifuging the plates, which allows results to be read after about 20 minutes.

\section{Material and methods}

Fujirebio TPHA kits were supplied by Diamed Diagnostics Ltd, Bootle, Merseyside. The modification requires extra absorbing diluent which is obtainable from the same company.
SERUM DILUTION

A 1 in 10 serum dilution is prepared using a compupet (General Diagnostics, Eastleigh, Hants). Five microlitres of serum are picked up and $50 \mu \mathrm{l}$ serum and diluent dispersed into a Tendix WHO plate. (Appleton-Woods, Birmingham). Five microlitres of this dilution are then transferred to a Terasaki plate (Gibco, Uxbridge).

\section{CELL DILUTION}

Sensitised sheep cells are used at a dilution of 1 in $7 \cdot 5$ after reconstitution. The test cells are reconstituted with $0.8 \mathrm{ml}$ distilled water, then $5.2 \mathrm{ml}$ absorbing diluent is added. Control cells (which come in a smaller quantity) are reconstituted with $0.5 \mathrm{ml}$ distilled water, then $3.2 \mathrm{ml}$ diluent is added. Cells are then left for $\mathbf{3 0}$ minutes before use.

\section{TEST PROCEDURES}

Five microlitres of test cells are added to each serum dilution using a Hamilton Terasaki dispenser. (VA Howe and Co Ltd, London). A positive control serum is titrated with test and control cells. The plates are then spun in a Beckman TJ6 centrifuge fitted with Micro-test plate carriers (Beckman-R I I Ltd, High Wycombe) at $2500 \mathrm{rpm}$ for one minute. Eight plates can be centrifuged at a time. The plates are left at room temperature at a $35^{\circ}$ angle for 20 minutes and the haemagglutination patterns are examined over a 
diffuse light source. In a positive reaction the cells form a ring around the base of each well; with a negative reaction, a crescent shaped pattern is formed.

Reactive sera are diluted 1 in 5 in control cell suspension and left to absorb for one hour at room temperature. They are spun and the supernatants titrated with test and control cells. Those that are still reactive at 1 in 10 are referred to Oxford Public Health Laboratory for confirmation.

\section{Results}

Over three months the "spin" modification and the formerly used "settle" method were performed in parallel on 21807 donor and antenatal sera. There were 16 confirmed positive reactions, all detected by both methods. Sixty six samples had to be repeated by both methods, a further 98 by the "spin" method, and 107 by the "settle" method. Comparison of the titres of the 16 positive sera showed that the "spin" method usually yielded titres of one doubling dilution less than the "settle" method. This was also the case with the kit positive control. "Spin" and "settle" methods were also compared using sera from Panel 405 of the Division of Microbiological Reagents and Quality Control. The results agreed with the above trend (table 3).

\section{Discussion}

The case for discarding cardiolipin tests and relying on TPHA for syphilis screening of blood donors has been made by Barbara et $a l,{ }^{7}$ and by the fact that in four years this centre has not found a single cardiolipin positive, TPHA negative case of syphilis. The time taken to perform the "settle" modification of TPHA, however, remained a problem that prevented us from relying on it exclusively. This has been solved by the introduction of the "spin" TPHA which compares very well with the established "settle" method and is rapid, sensitive, specific, cheap ( $0.98 \mathrm{p}$ per test) and well suited to mass screening. The slight reduction in sensitivity is compensated for by screening at $1 / 10$ rather than $1 / 16$ as used in the "settle" method. (Standard TPHA is usually used at $1 / 80$, but for screening blood donors it is better to be over sensitive.)

Costs can be further reduced in two ways. Nuttall showed that reconstituted Fujirebio cells can be frozen in aliquots and thawed for use, ${ }^{8}$ which means that the larger 500 test kits supplied by Diamed Diagnostics can now be used. This reduces the price per test to $0.75 \mathrm{p}$. A large part of the cost is in the extra buffer which must be bought for use with the compupet. A Microlab-M dilutor (VA Howe and Co Ltd, London), could make direct dilutions using no extra buffer and thus theoretically further reduce the price to $0.35 \mathrm{p}$ per test.

As well as the documented cost effectiveness in ante natal serology ${ }^{9}$ the screen for syphilis remains an important part of transfusion microbiology. Not only is it a legal requirement, but there is also the chance that a positive result could act as a surrogate marker for other infectious agents. Surrogate testing has been suggested for the human immunodeficiency virus (HIV $)^{10}$ and the agent of non-A, non-B hepatitis ${ }^{11}$; and the possibility should be considered that by excluding a TPHA positive donor, a centre might also be excluding a carrier of non-A, non-B hepatitis, or even someone who has acquired HIV, but in whom antibody is not detectable.

We thank the director of this centre, Dr CC Entwistle, for his helpful advice and encouragement.

\section{References}

1 Risseeuw-Appel IM, Kothe PC. Transfusion syphilis; a case report. Sex Transm Dis 1983;10:200-1.

2 Soendjojo A, Boedisantoso M, Ilias M, Rahardjo D. Syphilis d'emblée due to blood transfusion. British Journal of Venereal Disease 1982;58:149-50.

3 Does it make sense for Blood Transfusion Services to continue the time-honoured syphilis screening with cardiolipin antigen? Vox Sang 1982;41:183-92.

4 Barbara JAJ, Salker R, Lalji F, Davies TD, Harris JB. An economical, simplified haemagglutination test for mass syphilis screening. J Clin Pathol 1980;33:1216-8.

5 Puckett A, Pratt G. Modification of the system of screening for antisyphilis antibodies in a blood transfusion centre, featuring a modification of the Treponema pallidum haemagglutination assay. J Clin Pathol 1982;25:1349-52.

6 Sequeira PJL, Eldridge AE. Treponemal haemagglutination test. British Journal of Venereal Disease 1973;49:242-8.

7 Barbara JAJ, Salker R, Lalji F, Mochnaty P. TPHA compared with cardiolipin tests for serological detection of early primary syphilis. J Clin Pathol 1982;35:1394-5.

8 Nuttall P. Terasaki method for Treponema pallidum haemagglutination test using Fujrebio kit and serum dilutions in simple buffer. Transfusion Microbiology 1986;7:17-8.

9 Williams K. Screening for syphilis in pregnancy: an assessment of the costs and benefits. Community Medicine 1985;7:37-42.

10 Preventing AIDS transmission: should blood donors be screened? JAMA 1983;249:567-70.

11 Dodds TA, Sullivan RG, Beck JR. Cost effectiveness of screening donor blood for non-A, non-B hepatitis using alanine aminotransferase and hepatitis B core antibody. Transfusion 1986;26:597.

Requests for reprints to: Mr A Puckett, Regional Blood Transfusion Centre, John Radcliffe Hospital, Headington, Oxford OX3 9DU, England. 